\title{
3 Contextual Interaction Theory for assessing water governance, policy and knowledge transfer
}

\author{
Hans Bressers and Cheryl de Boer
}

\subsection{Introduction}

The successful transfer and eventual implementation of a policy is heavily dependent on the relationship between the context from which it came and that to which it is transferred. In Chapter 2, Vinke-de Kruijf and Özerol elaborates on the numerous ways in which this relationship is understood and analysed by different streams of literature. This chapter will provide a thorough explanation of one theoretical lens, which has been used extensively to examine water governance and implementation related processes: Contextual Interaction Theory (CIT). The basic premise from which CIT begins is that context matters, and quite a lot. While Chapter 2 focuses on the processes associated with the transfer of a policy, CIT is used here to provide a way to understand the internal processes that occur once the governance actors have decided to move forward to the implementation of the chosen policy. The purpose of introducing such a theory here is that it provides an analytical framework that helps to assess whether a policy transfer contributes to or damages conditions for successful water management. This chapter goes beyond addressing the likelihood of policy transfers and focuses on the degree of success of such transfers. Once a policy transfer is in principle accepted, like water management based at the river basin scale or stakeholder participation, it will be confronted with an existing governance regime. This confrontation can provide resistance or simply encapsulate what is new rather than really change to adapt to the new concepts or principles. Further, if the existing arrangements do undergo change there is no guarantee that the ideas that worked so well in the originating context will be able to contribute to the quality of water governance in the new context in which they are being applied.

Within policy studies there are wide ranges of frameworks, theories and methodologies available that can be used by researchers and practitioners in order to better understand how, when and why the context surrounding policies and projects affects inputs, processes and outcomes. CIT places the characteristics of the actors involved in the policy process at the centre of the analysis and provides a framework within which the influences of the 
external context can be understood. Through a more detailed understanding of how, where and why these actor characteristics are influenced by the external context, one can begin to draw some lessons related to effective policy transfer in water governance.

In the next section we first explain some basics of the actor-centred orientation of this framework and how actor characteristics ultimately determine the success of any policy and thus policy transfer. Thereafter the layers of context that affect these actors are presented. Policy transfers can be viewed as interventions into these contexts that not only need to assume their place therein, but also create synergy with existing elements to produce tangible improvements.

\subsection{Actor characteristics as the ultimate process setting}

When policy processes are viewed themselves as social interaction processes that are ultimately driven by the actors involved, as they are in Contextual Interaction Theory, it makes sense to place them and their main characteristics central stage in any analytical model, and to build any further explanation of the course and results of the process from that simple starting point. Throughout the history of policy implementation research, hundreds of crucial success factors have been proposed and used to analyse various cases. This can be theoretically interesting when trying to carve out the impact of a single factor. Practitioners however deal with situations in which numerous factors are simultaneously present and where different combinations arise. Even in a rather simple model of fifteen contextual factors each having only two possible values there are some 30,000 different possible combinations of circumstances. That model is unworkable as an analytical tool (Goggin, 1986), and excessive for use in practical analysis.

CIT asserts that since interaction processes are human activities, all influences - including those created by policy instruments - will flow via the key characteristics of the actors involved. These three characteristics are the cognitions, motivations, and power and resources of the actors. This approach enables an initial distinction of the inner core factors that is far more parsimonious. Figure 3.1 outlines these factors (inputs and outputs of the process are not shown in this figure).

The characteristics of the actors in the process are the ultimate driving forces of the process, and not mere consequences of the 'arena' in which the process takes place (cf. Ostrom, 1999). The resources of the actors provide them with capacity to act and power in relation to other actors. Motivations and cognitions also play an important role in creating productive or nonproductive settings for the process (see also further below). Resources become significant to the process when they are connected to cognitions and motivations. These three core actor characteristics represent different perspectives on social interaction processes and are exceptionally useful in explaining the dynamics of such processes (Owens, 2008). 


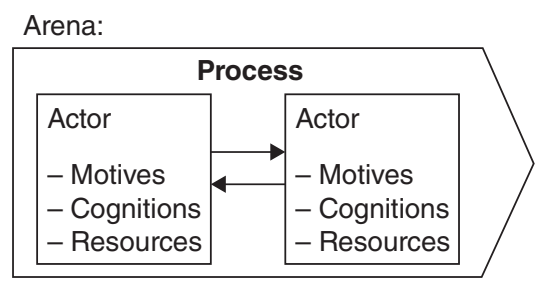

Figure 3.1 Process model with the actor characteristics used in Contextual Interaction Theory.

In this model peope constitute the 'actors', both individual and collective. Quite often however, these people represent organizations or groups and so often these organizations rather than the individual people are considered as the 'actors'. In Chapter 2, four types of actors are discerned that play a role in policy transfers, including supranational and international actors. In terms of the process, the relevant characteristics of representatives are often determined to such a large extent by the organization or group that they represent. As a result, a change of the individual actor is in most cases not likely to significantly change the setting of the process. 'Where one stands depends on where one sits' is an aphorism already cited by Allison (1971, p. 176) in his classic policy analysis. There is however also potential for the characteristics of individual people to have an impact in cases where they possess (or lack) diplomatic skills, creativity, motivation supported by personal enthusiasm, or where productive or destructive 'chemistry' exists between the individuals involved.

Summarizing this section: Contextual Interaction Theory explains the dynamics of social interaction processes and is intended to be simple and straightforward (Bressers, 2009). The theory's first main assertions are:

a Policy processes are not mechanisms, but social interaction processes between a set of actors (people, organizations). These policy processes include policy transfer processes and project realization.

b Many factors can influence the activities and interactions of these actors but only because and in as far as they change relevant characteristics of the involved actors.

c These characteristics are: their motives (which drive their actions), their cognitions (information held to be true, with which the situation is interpreted) and their resources (providing capacity and power) (see also Bressers, 2004).

d These three characteristics influence each other, but cannot be restricted to two or one without losing much insight (see Bressers, 2009).

e The characteristics of the actors shape the process, but are in turn also influenced by the course of and experiences in the process and can therefore gradually change during the process. 


\subsection{Layers of context and their relevance}

The three main actor characteristics are not only intrinsic to the actors and influenced by the process, but are also influenced by many external factors from a multilayered context. Part of that context is the case-specific context. This involves factors like the characteristics of the geographical place where the project is realized (Kotzebue et al., 2010). A special category is that of the case history consisting of previous decision-making and framing. This special type of case history affects the institutional arena for the process that influences which actors participate, to what extent and with what legal resources and expectations. A further layer of context is the structural context, with both the elements of governance and the relevant property and use rights (Bressers and Kuks, 2004). Next there is a less specified layer of wider contexts, within which the culture, and economic and technological developments and political system (Brynard, 2005, p. 659) are included.

The structural (governance) context related to for instance the national level is much more stable than the specific context, which applies to individual cases. The structural context will to a far lesser degree be influenced back by individual cases of policy transfer and implementation of the transferred options. In fact it is the essence of the difference between the specific and the structural context that the latter holds for, in principle, all similar cases and not only for any specific case. Nevertheless it too will gradually change in processes on a larger scale than the specific case, but

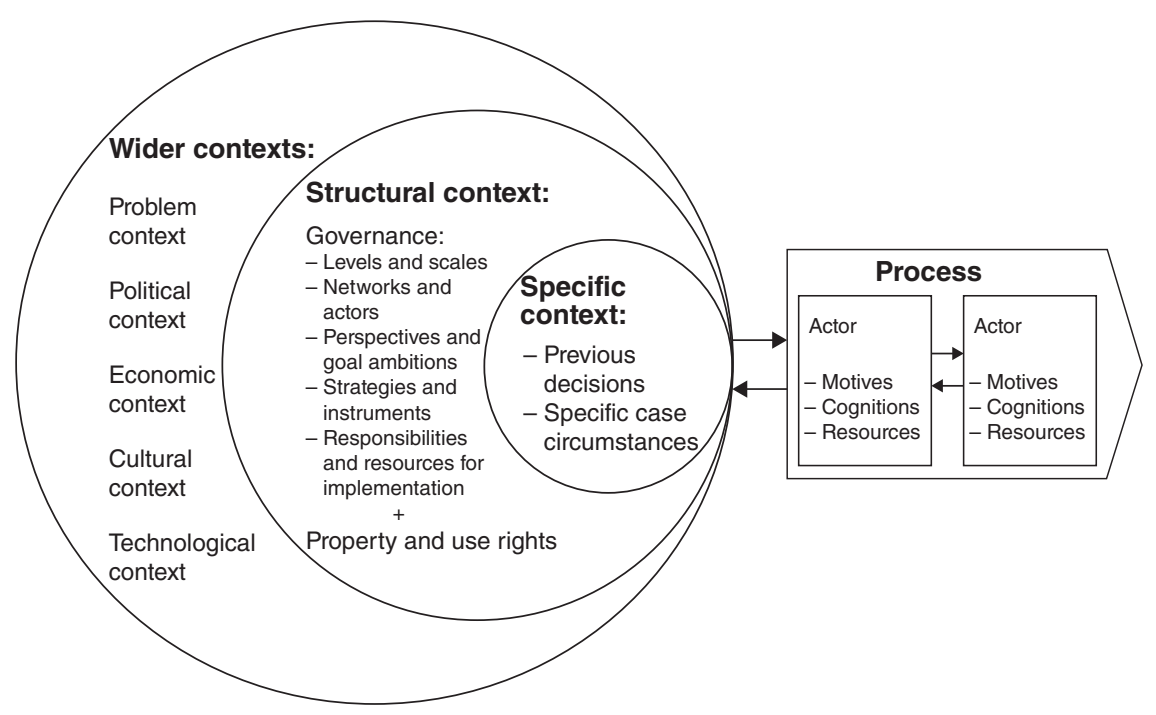

Figure 3.2 Layers of contextual factors for actor characteristics (source: Bressers, 2009). 
with similar dimensions of motivational, cognitive and resource developments in response to external influences and internal frictions (Bressers and Kuks, 2003, p. 74-83; Costejà Florensa, 2003). These developments are not always coherent across the various elements of governance (compare Howlett and Cashore, 2007). The elements of governance also influence each other when new situations are encountered. For instance the degree of interconnectedness and cohesion of the network relations influence the characteristics of instruments in instrument selection processes (Bressers and O'Toole, 1998, 2005; Ligteringen, 1999).

The specific context is not entirely determined by the structural context. A lack of interconnectedness and cohesion of the network relations at the national governance level need not be replicated among the constellation of the actors involved. More generally in the context of a specific case, the structural relations between levels, actors, goals, instruments and resources will be adapted to the specific case in as far as the actors strive for this and it is possible. When the process continues for a longer period of time, or is a process in a series of similar processes that together give enough time, this adaptation is feasible. It can be worthwhile to attempt to build for instance better networked relations among the actors involved in this series of processes. Such collaborative policy networks at the case level can have important self-reinforcing characteristics (DeLeon and Varda, 2009). The strategies used by the actors involved for this 'metaprocess' are discussed later in this chapter.

The structural context also consists of the valid property and use rights system associated with land, water and other relevant resources (e.g. Ostrom, 1999). The relevant structural context - or 'regime' - is thus a combination of both public governance and property and use rights (Knoepfel and Nahrath, 2005; Knoepfel et al., 2007) and the related exclusion of uses and access granted to users. Policy options for water management that can work well in their area of origin can be a complete mismatch in another context where the property and use rights related to the protection of private land are much stronger.

The 'five multiplicity aspects of governance' form an important part of the structural context (Bressers and Kuks, 2003). Governance is not used here as a normative concept or as a hypothesis of developments in government-society relationships (Howlett, 2011, pp. 7-10, see also Chapter 2 where the concept of 'good water governance' is elaborated upon), but as a neutral, yet enlarged understanding of the scope of the concept of 'policy'. The five elements of governance take the form of:

1 Scales and levels: governance assumes a multilevel character of all scales (jurisdictional, spatial, temporal etc.); in policy transfer processes often a transnational or international scale is included.

2 Actors and networks: governance assumes the multi-actor character of the relevant network(s). 
3 Perceptions of the problem and goal ambitions (not just the objectives): governance assumes the multifaceted character of the problems and ambitions.

4 Strategies and instruments: governance assumes the multi-instrumental character of the strategies of the actors involved.

5 Resources and responsibilities for implementation: governance assumes the complex multiresource basis for implementation.

In the context of a policy being transferred from one water management regime to another, these various aspects can guide an analysis of how similar and different the important aspects of the two governance contexts are. This can provide important insights for understanding how the implementation process related to the transferred policy will be influenced by the governance regime. In addition to using these aspects to study the influences of the structural context, a number of qualities of the governance regime can also be analysed and be used to understand its influence on the interaction processes. These qualities, extent, coherence, flexibility and intensity, are described in the following sections.

Around the structural context there is yet another more encompassing wider context circle of political system, sociocultural, economic, technological development and problem contexts. Some cultural settings can for instance make hierarchical approaches less feasible, or make some degree of social control obsolete, (Schwarz and Thompson, 1990; Thompson et al., 1990; Wildavsky, 1982).

\subsection{Extent and coherence as requirements for effective water resource management}

The structural context influences the process not only through its direct contents, but also though its extent and coherence (Knoepfel et al., 2001, 2003; Bressers and Kuks, 2004). The extent is a quality of the regime that refers to its completeness. The coherence is a quality that expresses the degree to which the various elements of the regime are strengthening rather than weakening each other. The success of policy transfers is partly dependent on whether these qualities are improved or decreased by the transfer.

A regime increases its extent and consequently becomes more complex when more levels and scales are involved, more actors are involved, more perceptions of the problem and accompanying goals are involved, more instruments are part of the policy mix and more organizations share responsibilities for implementation. The most eminent feature of extent is however the gradual increase of the domain of the regime, which consists of the uses and users regulated by one or more parts of the regime. With this also comes an increase in relevant property and use rights. This is then viewed as an increase in the crucial variable of extent. Regimes with an insufficient extent are by definition weak as guardians of sustainable 
resource use, since some relevant parts of the domain are unregulated. Policy transfers tend to increase the extent of the governance regime, since a cognition that important aspects are lacking in relation to the water problems at stake can be a main driver to engage in such transfers.

Complexity, as a characteristic of the governance regime, need not be harmful to the overall water governance processes present in a particular case (de Boer and Bressers, 2011). Logically, growing complexity develops as an answer to real needs and issues. Societies in modern times have generally grown towards increased complexity. Increased populations, borders, overlaps, activities, rivalries etc. are a fact of our current living environments. A growing complexity in governance can be viewed as a natural adaptation to that development (Gerrits, 2008; Teisman et al., 2009). Many external change agents, such as technological developments, add new scales, new actors, new problem perceptions, new instruments and new responsibilities to the existing ones.

While the term 'integration' is common in policy papers (e.g. those on 'integrated water resources management'), coherence is used here instead, for the reason that, in policy papers the term integration (e.g. in 'integrated water management') is used in a sense that implicitly or explicitly includes an increase in the domain of the regime (the extent increased to all relevant users and uses). Therefore, we believe that integration as it is used in the policy sphere is a combination of what we call extent and coherence. In Chapter 2, the inherent tension between those two aspects in the concept of integrated water resources management (IWRM) is described. For the sake of conceptual clarity and the possibility of adapting to the meaning of the term integration in policy practice, we use the terms extent and coherence when appropriate, and reserve 'integration' for the combination of the two.

When more than one layer of government influences the management of the same water or other natural resource (as is often the case), then coherence means, among other things, that the activities of these layers of government are recognized as mutually dependent and influencing each other's effects. Likewise if more than one governance scale is relevant the interaction effects between those scales should be considered. When more than one actor (stakeholder) is involved in the policy, coherence means that there is a substantial degree of interaction in the policy network; preferably productive interaction providing coordination capacity. When more than one use or user is causing the problem of unsustainable resource use for example, coherence means that the various resulting objectives are analysed in one framework so that deliberate choices can be made if and when goals and/or uses are conflicting. When the actors involved have problem perceptions that start from different angles, coherence means that they are capable of integrating these to such an extent that a common ground for productive deliberation on ambitions is created. The same holds for instrumental strategies that are used to attain the different 
objectives, as well as for the different instruments in a mix to attain one of these objectives. Coherence of the organization of the implementation process means that responsibilities and resources are coordinated, or the responsible actors themselves are coordinated.

With more coherence in the public governance component of the regime, the goals of the actors involved in the process are less likely to be in discord. All elements of a more coherent regime can be assumed to contribute to a lowered degree of experienced uncertainty, an increase in information exchange, and a lower degree of distrust. This implies that a more coherent public governance component of the regime can outperform a regime with an equal degree of extent, yet more fragmentation. While policy transfers are assumed to generally increase the extent and thereby the complexity of the governance regime, the coherence with the existing elements of governance could actually be lowered rather than raised. In such cases, the overall effectiveness of water management will not improve, and could be in danger of deteriorating. Hence the degree of ultimate success of the policy transfer is also dependent on the degree to which it can be introduced in such a way that it improves rather than decreases governance coherence.

This leads to some further assertions:

f Regimes with a deficient extent are more likely to lead to a degradation of water resources or an inability to protect the ecological functions of the resource, than are regimes with a larger extent.

g Regimes with a large extent, but with low coherence are more likely to lead to degradation of natural resources or an inability to protect the ecological functions of the water resource, than regimes with a similar extent but a higher degree of coherence.

These last assertions have been tested as hypotheses and generally confirmed in a six country, twenty-four cases study on tributary river basin management (Bressers and Kuks, 2004). However the relation between the growth of the extent of the regime and the improvement of sustainability estimates proved to be rather weak and hardly significant. The relation between the general assessment of regime change towards more integration (extent and coherence taken together) and the assessment of sustainability improvements is however much stronger (Spearman's rho=0.533, $p=0.004)$. Of the separate regime aspects, by far the most important factor was the coherence of public governance. It correlated even more strongly with the assessment of sustainable resource use than the general regime change $(r h o=0.635)$. Another example confirming the CIT relationships between extent and coherence of governance regimes, the motivation, cognitions and resources of actors and the policy results, can be found in a separate study on Greece and the implementation of the EU Water Framework Directive (Kampa, 2007). 


\subsection{Governance flexibility and intensity as requirements for adaptive management}

Extent and coherence have been shown to be important regime qualities in more or less steady state situations or when one wants to compare the before and after examples of policy transfers in water management. Following the general acceptance of the integrative ambitions of IWRM it was observed that the increased complexity leads to uncertainty and unpredictability and that water management thus needs to be prepared to avoid threats and use opportunities as they arise. This includes trying not only to see the reality as a field of obstacles, but also as a terrain of potential - often unexpected - opportunities and being adaptive enough to use every 'window of opportunity' to bring the ultimate purpose closer to realization. Sometimes the above is called Adaptive Water Management (AWM) (Lulofs and Bressers, 2010), though others emphasize the adaptive capacity of the water system itself as a core issue of this approach (PahlWostl et al., 2005). In a highly dynamic process situation in which success depends on quick and timely adaptive action, new regime qualities become important for supporting water management processes. Thus also the success of transferred policy options is partly dependent on the degree to which such governance regime qualities are reinforced or hampered. This section provides a description of the value added when flexibility and intensity are added as regime qualities when studying complex and dynamic policy processes and the role of policy transfers therein.

First, flexibility is important as it indicates to what degree the relevant actors have formal and informal liberties and stimuli to act. The attention given to the flexibility of the regime is approached on the basis of the documentation about the regime elements, as well as from a bottom up perspective. Success and failure factors of the actual projects can be rightfully attributed to inflexibilities in provincial, national and ultimately supranational policies. What is also interesting is how the latter are moderated by national and subnational regimes.

Flexibility as defined in de Boer and Bressers (2011, p. 92) is 'the degree to which the regime elements support and facilitate adaptive actions and strategies in as far as the integrated (among others multi-sectoral) ambitions are served by this adaptiveness'. Consequently it is also the degree to which hindrances for such adaptive behaviour are avoided. The addition 'in as far as ...' is needed to discern governance and policy that is just weak from a genuine attempt to make the most of the situation. The term 'integrated (among others multi-sectoral) ambitions' refers here to the integrated multifunctionality of the various interests that exist in the project or policy arena. In cases of water policy transfer, there are likely to be many other non-water-related interests that will be affected throughout the policy process and as a result of the resource use arrangement that is in place 
following implementation. Thus, the context will determine to what extent new and existing uses need to be reconciled during this process.

The value of flexibility must be understood in connection with the level of the other qualities also present in the regime. Flexibility needs at least a certain degree of coherence to be built upon. Otherwise, when it is just extensive discretion and self-reliance for water managers there is a high risk that a fragmented and a weak form of water management would result.

The flexibility of the regime can be described in terms of the five elements of governance. The following paragraphs elaborate on flexibility in terms of the five aspects of governance (see also de Boer (2012) for further development of this concept):

1 A regime is more flexible in as far as the relationships between the levels and scales involved are more based on decentralization of power, without upper levels withdrawing support. This is closely related to empowering rather than controlling relations, and thus on trust.

2 A similar feature describes flexible regimes in terms of actor relations in the policy network. The combination of giving leeway to each actor group to optimize its contribution to the whole programme while still viewing the programme as a joint effort qualifies as flexibility.

3 In terms of general problem perception and goal ambitions flexibility implies that these in their variety are not only integrated into a sort of common denominator (like with coherence), but also that these mixtures are allowed to be different in emphasis according to the opportunities of the context in the various concrete situations. This implies some acceptance of uncertainty and openness to emergent options, which again relates to trust.

4 The instruments and their combinations in policy strategies or mixes are more flexible in as far as means from different sources (like public policies and private property rights) may be used as well as indirect means (here relating to opening or improving options for the use of means that more directly serve the goals) are available and allowed to be used.

5 The flexibility of the organization responsible for the implementation - the responsibilities and resources given by the policy programme(s) - can be measured by the discretion available to pool resources like funds and people with those of others to serve integrated projects and to be held accountable on the basis of the balanced virtues of the achievements (as in an integrated project), rather than on the basis of separate performance criteria.

There is often a highly dynamic and change-oriented nature to many policies that aim to improve general water governance processes or the use of water resources. This is the case since water management often influences many societal issues related to health, economic development, 
environmental resilience etc. As such, there is yet another regime quality that can be influential for the practical process of implementing water related policies. That is the obvious, but no less important aspect of intensity. Intensity is 'the degree to which the regime elements urge changes in the status quo or in current developments' (de Boer and Bressers, 2011, p. 93). The 'amount of change' is thereby measured in analogy with Newton's 'law of inertia', respect to the degree of energy it takes to produce the change. In systems theory, induced changes will typically meet negative feedback loops, weakening their impact, while in some cases positive feedback loops creating dynamics for permanent change are also conceivable (True et al., 1999; Bressers and Lulofs, 2009). In policy studies terms, intensity is related to the size of the task that is required to create new dynamics by creative cooperation, or conflict. Conservative motivations often need to be changed or overruled by power. Cognitive boundary judgements regarding the issues at stake require broadening. New resources need to be made available and combined with old ones. In other words: with more intensity the urge to use clever adaptive strategies to deal with and change the setting of the process increases.

The five elements of governance can also be used to highlight the important intensity related aspects of the governance regime. By doing so we find that:

1 Intensity is greater in as far as upper levels are more deeply involved.

2 Actors that are also powerful in other domains are more deeply involved in the relevant policy network for the issue at stake.

3 The issue plays a larger role in the public debate leading to a greater openness to try to push developments away from a business-as-usual track (thus with more ambitious goals).

4 The instruments made available to be used include more interventionist ones.

5 The amount of resources made available for implementation is larger. (See also de Boer (2012) for further development of this concept.)

We acknowledge that there is an implicit potential tension between this 'quality' of the regime and the previous one of flexibility. This is related to the eternal dilemma of the 'quest for control' involving distrust, versus the 'learning while doing approach' involving trust. When an actor wants to achieve a great deal of change this can increase the distrustful tendency to try to control the related or influencing processes from the top down, which leads to a decrease in the flexibility. However in complex and dynamic situations decreasing flexibility is often detrimental since arising opportunities are missed or not created and developing obstacles often cannot be foreseen. However when there is sufficient trust in the implementers' motivation to genuinely work on the matter, flexibility in the governance regime can be an important resource. 
When the change striven for is multidimensional, e.g. involving multiple policy sectors, synergies should be welcomed and trade-offs accepted when necessary (de Boer et al., 2011). While in its definition 'flexibility' is shielded from mere discretion that would also accept implementers doing nothing, there remains a natural limit to flexibility as a positive force. When multiple policy sectors are involved in the water management process, an integrated vision is helpful for guiding the process, preventing extreme imbalances (coherence) or the exclusion of essential sectors (extent). Inevitably there will be some limitations to flexibility induced by this. Here the regime quality of flexibility is restricted to a certain degree by the regime quality of (multi-sectoral) interregime extent and coherence.

Some last assertions of Contextual Interaction Theory specified here are:

$\mathrm{h}$ While the extent and coherence are crucial qualities of the structural context when stabilization and protection of a resource is attempted through the policy intervention, other qualities should be added when change and the creation of new resources are desired.

i The first additional quality is the flexibility of the regime; the degree to which the regime allows and facilitates the case-specific variation and boundary spanning strategies of actors needed for adaptive management in as far as the change ambitions are served by this adaptiveness. Under the conditions of sufficient motivation of the implementers and sufficient interregime extent and coherence more flexibility will lead to better adaptive strategies and thereby to improved results.

$\mathrm{j}$ The second additional quality is the intensity: to what degree is the change striven for a deviation from 'business as usual'? The greater the intensity, the more resistance that will have to be overcome (negative feedback loops), but sometimes also more enthusiasm can be provoked (positive feedback loops).

\subsection{Adaptive strategies to deal with complex and dynamic settings}

The use of adaptive management is presented as an essential remedy for the problems seen around the world related to access to and management of water (Pahl-Wostl et al., 2005; Bressers and Lulofs, 2010b). This adaptive management is itself however not a process without its own internal struggles and various strategies exist with which to accomplish its end goals. The strategies that develop can be a response to unsatisfactory processes, though with experienced actors they can also be preventative, attempting to avoid an unproductive setting before it becomes a fixed context for the ensuing process. Such strategies rarely have a 'the more the better' character. In fact their (degree of) application needs to be continuously balanced with the evolving threats and opportunities of the context, that often itself is in flux for more reasons than deliberate strategies of the actors involved. These strategies can involve more than just the motivations, cognitions and 
resources concerning the issues at stake. The actors can also try to change the specific context of the process. Sometimes it is possible to bring in new actors or exclude existing ones or try to redefine the process and its relevant issues differently to shift it to another arena with a (partially) different governance context (see for an elaboration Bressers and Lulofs, 2010a, pp. 27-30). Some examples which have been observed are:

1 adding new actors; these can include policy brokers or 'inviting oneself' to consultations among other actors on new plans, or more generally keeping regular interaction with other potentially relevant actors even when no immediate issue is calling for attention, this way providing better network relationships not on the level of the general governance context but much closer to the level of the specific case;

2 creating new arenas by adding new meeting points such as through the choice of a particular administrative setting (e.g. a voluntary process or under the institutional setting of a certain law) for the process when possible or by installing working groups or committees;

3 creating new cognitions by introducing new information, spreading information and perceptions by new catchy key words and metaphors, involving the media etc. (compare van Buuren, 2006);

4 creating new motivations by creating salience among others through luring with resources, or by promoting with positive intermediate results; and

5 adding new resources and power bases for instance by exchanging relatively flexible ones (like money) in advance for relatively fixed or scarce ones, such as land ownership.

The use of strategies is often not deliberate or precise. Understanding of strategic options must be accompanied by the presence of the necessary and efficient tools. These options also require skilful actors to enable their meaningful exploitation (Hermans, 2005). In complex systems, many developments are 'emergent'; quite unpredictable consequences of a multiplicity of factors and circumstances. Consequently, the use of strategies is often spontaneous and time-pressured. Moreover, it can be quite wise to simultaneously use diverse strategies and include a degree of 'redundancy' in order to create fall-back options when one of the strategies does not have its intended or desired effect, as the literature also states about water management institutions (Constanza et al., 2001; Low et al., 2003; Ostrom, 2005). While it is important to keep various water management options open as long as possible, in order to provide a sufficient degree of accountability towards elected representatives, it is necessary to work within an agreed dynamic framework for various stages of action (Koppenjan $e t$ al., 2009). Such accountability need not be at the expense of organizational capacity when the performance criteria are under reflexive adjustment and do not remain fixed regardless of new situations (Pires, 2011). 'Good water 
management will only become a reality once we recognize that water managers have complex duties' (Figuères et al., 2003).

Vinke-de Kruijf and Özerol discuss in Chapter 2 some insights from the realm of technology transfer that were later applied to the realm of water resources management. When we look at the strategies that actors in dynamic situations apply to themselves internally, by trying to prepare themselves to take advantage of these opportunities for improved interaction in complex settings, we see these concepts as connecting these two aspects of the policy transfer and water management implementation process. Internal strategies are seen as an attempt to increase the actor's receptivity. Jeffrey and Seaton (2004) coined the term receptivity as not only dependent on the degree of exposure to new knowledge, but also more specifically on the way the actor can associate and exploit new knowledge around existing knowledge, activities and objectives. This requires that the actor 'lets the outside come in', and can open and regroup their understandings to include reckoning with the new knowledge. Thus, receptivity is not a form of passiveness or weakness. It is a form of alertness and openness towards the context that enables well-targeted innovative and adaptive action by self-confident people and organizations.

Receptivity tends to play a major role in recognizing the opportunities that can be seen due to the enlarged domain perception and then used to create synergies with the activities of other actors. If both parties perceive potential synergy, meaning that they see joint chances for cooperation, boundary spanning is more likely to create productive linkages (Bressers and Kuks, 2004, pp. 259-262). This perception in turn reinforces the degree of openness towards enlarged domain boundaries. If one or both parties consider the situation purely as rivalry or even mutually exclusive, one might even observe attempts to reinforce existing boundaries or bring up new boundaries in order to keep domains apart or separate them. Jeffrey and Seaton (2004) discern four phases of receptivity that can also be seen as permanent variables: awareness, association, acquisition and application (see also Bressers, 2011). In the cognitive system, these can be linked to, respectively, the observations, the filtering through frames of reference (including boundary judgements on what belongs to the subject of the process at stake and what not), the interpretations of reality and the impacts of the cognitive system on motivation, capacity and the process itself.

For the purposes of understanding the specific aspects of implementing a transferred water policy in a multidisciplinary and functional context, we use an expanded definition of receptivity:

the ability to combine new information with existing cognitions, to recognize new goals as matching existing motivations or the values behind them and to recognize the opportunities of new resources or combinations with existing resources to optimize their capacity and power

(De Boer and Bressers, 2011, p. 90) 
A greater likelihood for productive interaction processes under one of the various combinations of motivations, cognitions and resources of the actors involved might result from an increase in such receptivity.

Receptivity can be both a quality of people and organizations. While we typically describe receptivity as an organizational characteristic, we acknowledge the importance of skilled, experienced and open-minded project managers that fulfil important roles as 'boundary spanners'. The receptivity of an organization is partly important to enable them to fulfil this function.

Like the arena and constellation of actors and their characteristics, the receptivity of an organization is not entirely fixed and can thus be altered in the course of time by external factors and deliberate internal strategies. It is crucial that an organizational philosophy is oriented towards external cooperation for instance through rewarding project managers that are communicative, flexible and entrepreneurial.

Summarizing this section, some further assertions in CIT are:

$\mathrm{k}$ The rules of the game that e.g. provide or restrict resources are often not static but themselves subject to change partly by external strategies by actors in the process unless they are firmly fixed by the regime. The same holds for the actor constellation in the process.

1 The setting of actor characteristics that impacts on the course and result of the process is not only dynamic due to external factors, but can also to some extent be manipulated by clever external strategies of the actors during the process (these are often forms of 'boundary spanning' - see Bressers and Lulofs, 2010b).

$\mathrm{m}$ Since adaptive boundary spanning strategies often require concerted actions by more than one individual person, this also draws attention to the internal organization of the actor ('actors' in most analyses are in fact 'corporate actors': organizations or parts of organizations). Here the receptivity of these actors and actor organizations is relevant.

$\mathrm{n}$ This receptivity can also be positively influenced by internal strategies of actor organizations, which promote continuous learning, consciously dealing with uncertainty, and stimulating mutually supportive intraorganizational relations.

\subsection{Concluding remarks: contextual factors set the conditions for policy and knowledge transfers}

Understanding the various impacts from various perspectives and influencing factors - particularly in the complex policy realm of water governance - is highly dependent on context. The task stressed here is to develop an approach which assists us in knowing 'what works, where, when and how in transferring lessons in water management?' By being open to a large variety of contextual factors, but nonetheless channelling them 
through a limited number of 'core characteristics' that build a deductive explanatory framework, the approach that is provided in this chapter strives to achieve an understanding of the water management implementation processes which is simultaneously concise and more generally applicable. This framework supports an assessment of the degree to which policy transfers can be viewed as improvements that contribute to, rather than hamper, successful water management.

Reasons for using such a framework include being able to see the influence of different characteristics which arise from varying contexts and how they play a prominent role in the final product without attempting to cancel out the important local effects. The context is not only important in as far as how it impacts the original intent of the policy, but also gives it a place of importance in the expectation of the more widely defined preferred outcome. This form of utility is key to understanding the process and influences on the given actors involved in the transfer and implementation processes. Importantly, this model can also be used to describe the various interactions and influences between the actor (organization) of interest and other actors, regime contents and qualities under dynamic conditions and can focus on the impacts of these dynamics.

The policy process as seen to occur between the external context and the target actors is explored to show how the receptivity (characterized by awareness, association, acquisition, adoption) of the target organization can work as a catalyst to align the external and internal contexts to enable successful implementation of transferred policy options. Changes in context occur continually in any policy process due to the complexity of the regime or the dynamic nature with which actors interact.

The model developed in this chapter is used by a number of authors in the following chapters of this book in their explorations of particular experiences in knowledge and policy transfer in the field of water governance. It is thus provided here as a basis upon which different cases can be compared, however a number of the chapters make use of other appropriate models and frameworks. We have encouraged the use of these different approaches in this book and provide some conclusions in the final chapter about the value of having a number of different lenses from which to view contemporary water governance practices as well as the plethora of real-world case examples. The following chapters in this book provide insights on cases where policy and knowledge transfers are being undertaken as a way of addressing global and local water resource use and management challenges. This chapter presents a way of thinking about what happens when these policies take hold of resources and attention through more local implementation actions and water management projects. 


\section{References}

Allison, G.T. (1971) Essence of Decision: Explaining the Cuban Missile Crisis, Little, Brown and Company, Boston, MA.

Bressers, Hans (2004) 'Implementing sustainable development: How to know what works, where, when and how', in William M. Lafferty (ed.) Governance for Sustainable Development: The Challenge of Adapting Form to Function, Edward Elgar, Cheltenham, Northampton MA, pp. 284-318.

Bressers, Hans (2009) 'From public administration to policy networks: Contextual interaction analysis', in Stéphane Narath and Frédéric Varone (eds) Rediscovering Public Law and Public Administration in Comparative Policy Analysis: A Tribute to Peter Knoepfel, Presses polytechniques, Lausanne, pp. 123-142.

Bressers, H.T.A. and Kuks, S.M.M. (2003) 'What does "governance" mean? From conception to elaboration', in H. Bressers and W.A. Rosenbaum (eds) Achieving Sustainable Development: The Challenge of Governance across Social Scales, Praeger Publishers, Westport, CT.

Bressers, Hans and Kuks, Stefan (eds) (2004) Integrated Governance and Water Basin Management: Conditions for Regime Change and Sustainability, Kluwer Academic Publishers, Dordrecht/Boston, MA/London.

Bressers, Hans and Lulofs, Kris (2009) 'Explaining the impact of the 1991 and the 2000 firework blasts in the Netherlands by the core of five policy change models', in Giliberto Capano and Michael Howlett (eds) European and North American Policy Change: Drivers and Dynamics, Routledge, Abingdon and ECPR, New York, pp. 15-42.

Bressers, Hans and Lulofs, Kris (2010a) 'Analysis of boundary judgments in complex interaction processes', in Hans Bressers and Kris Lulofs (eds) Governance and Complexity in Water Management, Edward Elgar, Cheltenham, pp. 17-32.

Bressers, H. and Lulofs, K. (eds) (2010b) Governance and Complexity in Water Management, Edward Elgar, Cheltenham.

Bressers, Hans and O'Toole, Laurence J., Jr. (1998) 'The selection of policy instruments: A network-based perspective', Journal of Public Policy, vol. 18, no. 3, pp. 213-239.

Bressers, Hans and O'Toole, Laurence J., Jr. (2005) 'Instrument selection and implementation in a networked context', in Pearl Eliades, Margaret M. Hill and Michael Howlett (eds) Designing Government: From Instruments to Governance, McGillQueen's University, Montreal/Kingston/London/Ithaca, NY, pp. 132-153.

Bressers, N. (2011) 'Co-creating innovation: A systemic learning evaluation of knowledge and innovation programmes', PhD thesis, Erasmus University Rotterdam.

Brynard, P. (2005) 'Policy implementation: Lessons for service delivery', Journal of Public Administration, vol. 40, no. 4.1, pp. 649-664.

van Buuren, Arwin (2006) Competente besluitvorming (Competent Decision-Making), Erasmus University, Rotterdam.

Constanza, R., Low, B., Ostrom, E. and Wilson, J. (2001) Institutions, Ecosystems and Sustainability, Lewis, New York.

Costejà Florensa, Meritxell (2003) Institutional dynamics: First steps toward developing a logic sequence for studying institutional change, Paper conference of Workshop in Political Theory and Policy Analysis, Bloomington, IN, 13-15 December. 
de Boer, Cheryl (2012) 'Contextual water management: A study of governance and implementation processes in local stream restoration projects', $\mathrm{PhD}$ thesis, University of Twente, Enschede, pp. 1-265.

de Boer, C. and Bressers, H. (2011) Complex and Dynamic Implementation Processes: the renaturalization of the Dutch Regge River, University of Twente with the Dutch Water Governance Centre, Enschede.

de Boer, Cheryl, Bressers, Hans and Kuks, Stefan (2011) 'Coordination of policies and governance: Regime requirements in Dutch freshwater management', Policy Quarterly, vol. 7, no. 4, pp. 3-9.

DeLeon, Peter and Varda, Danielle (2009) 'Toward a theory of collaborative policy networks: Identifying structural tendencies', Policy Studies Journal, vol. 37, no. 1, pp. 59-74.

Figuères, Caroline, Rockström, Johan and Tortajada, Cecilia (2003) 'Conclusion: The way forward', in Caroline Figuères, Johan Rockström and Cecilia Tortajada (eds) Rethinking Water Management: Innovative Approaches to Contemporary Issues, Earthscan, London, pp. 228-236.

Gerrits, Lasse (2008) The Gentle Art of Coevolution, EUR, Rotterdam.

Goggin, Malcolm L. (1986) 'The 'too few cases/too many variables' problem in implementation research', Political Research Quarterly, vol. 39, no. 2, pp. 328-347.

Hermans, Leon M. (2005) Actor Analysis for Water Resources Management, Eburon, Delft.

Howlett, Michael (2011) Designing Public Policies: Principles and Instruments, Routledge, Abingdon.

Howlett, Michael and Cashore, Ben (2007) The dependent variable problem in assessing policy change: Re-conceptualizing the orthodox understanding of policy dynamics, paper ECPR Joint Sessions, 7-12 May, Helsinki.

Jeffrey, P. and Seaton, R.A.F. (2004) 'A conceptual model of "receptivity" applied to the design and deployment of water policy mechanisms', Environmental Sciences, vol. 1, no. 3, pp. 277-300.

Kampa, Eleftheria (2007) Integrated Institutional Water Regimes: Realisation in Greece, Logos, Berlin.

Knoepfel, Peter and Nahrath, Stéphane (2005) Sustainable Management of Natural Resources: From Traditional Environmental Protection Policies Towards Institutional Natural Resource Regimes (INRR), Idheap, Chavannes-Lausanne.

Knoepfel, Peter, Kissling-Näf, Ingrid and Varone, Frédéric (2001) Institutionelle regime für natürliche ressourcen, Helbing \& Lichtenhahn, Basel.

Knoepfel, Peter, Kissling-Näf, Ingrid and Varone, Frédéric (eds) (2003) Institutionelle Ressourcenregime in Aktion/Régimes institutionnels de ressources naturelles en action, (Institional Resource Regimes in Action), Helbing \& Lichtenhahn, Basel/Genf/ München.

Knoepfel, Peter, Nahrath, Stéphane and Varone, Frédéric (2007) 'Institutional regimes for natural resources: An innovative theoretical framework for sustainability', in Peter Knoepfel, Environmental Policy Analyses: Learning from the Past for the Future: 25 Years of Research, Springer, Berlin, pp. 455-506.

Koppenjan, Joop, Kars, Mirjam and Van der Voort, Haiko (2009) 'Vertical politics in horizontal policy networks: Framework setting as coupling arrangement', Policy Studies Journal, vol. 37, no. 4, pp. 769-792. 


\section{H. Bressers and C. de Boer}

Kotzebue, J.R., Bressers, H.T.A. and Yousif, C. (2010) 'Spatial misfits in a multi-level renewable energy policy implementation process on the Small Island State of Malta', Energy Policy, vol. 38, no. 10, pp. 5967-5976.

Ligteringen, Josee (1999) 'The feasibility of Dutch environmental policy instruments', PhD thesis, University of Twente, Enschede.

Low, B., Ostrom, E., Simon, C. and Wilson, J. (2003) 'Redundancy and diversity: Do they influence optimal management?' in F. Berkes, J. Colding and C. Folke (eds) Navigating Social-Ecological Systems, Cambridge University Press, Cambridge, pp. 83-105.

Lulofs, Kris and Bressers, Hans (2010) 'Innovations in water management requiring boundary spanning: Roots and concepts', in H. Bressers and K. Lulofs (eds) Governance and Complexity in Water Management: Creating Cooperation Through Boundary Spanning Strategies, Edward Elgar Publishing, Cheltenham/ Northampton, MA, pp.1-16.

Ostrom, Elinor (1999) 'Institutional rational choice: An assessment of the institutional analysis and development framework', in Paul Sabatier (ed.) Theories of the Policy Process, Westview Press, Boulder, CO, pp. 35-71.

Ostrom, Elinor (2005) Understanding Institutional Diversity, Princeton University Press, Princeton NJ.

Owens, Katharine (2008) 'Understanding how actors influence policy implementation: A comparative study of wetland restorations in New Jersey, Oregon, The Netherlands and Finland', PhD thesis, University of Twente, Enschede.

Pahl-Wostl, C., Downing, T., Kabat, P., Magnuszewski, P., Meigh, J., Schlueter, M., Sendzimir, J. and Werners, S. (2005) Transition to Adaptive Water Management, NeWater Working Paper X, Institute of Environmental Systems Research, University of Osnabrück, Osnabrück.

Pires, Roberto R.C. (2011) 'Beyond the fear of discretion: Flexibility, performance, and accountability in the management of regulatory bureaucracies', Regulation and Governance, vol. 5, no. 1, pp. 43-69.

Schwarz, Michiel and Thompson, Michael (1990) Divided We Stand: Redefining Politics, Technology and Social Choice, Harvester Wheatsheaf, New York.

Teisman, Geert, Gerrits, Lasse and Buuren, Arwin van (2009) 'An introduction to understanding and managing complex process systems', in Geert Teisman, Lasse Gerrits and Arwin van Buuren (eds) Managing Complex Governance Systems, Routledge, New York, pp. 1-16.

Thompson, Michael, Ellis, Richard and Wildavsky, Aaron (1990) Cultural Theory, Westview Press, Boulder, CO.

True, J.L., Jones, B.D. and Baumgartner, F.R. (1999) 'Punctuated equilibrium theory: Explaining stability and change in American policy making', in Paul A. Sabatier (ed.) Theories of the Policy Process, Westview Press, Boulder, CO, pp. 97-115.

Wildavsky, Aaron (1982) 'The three cultures: Explaining anomalies in the American welfare state', Public Interest, no. 69 , pp. 45-58. 